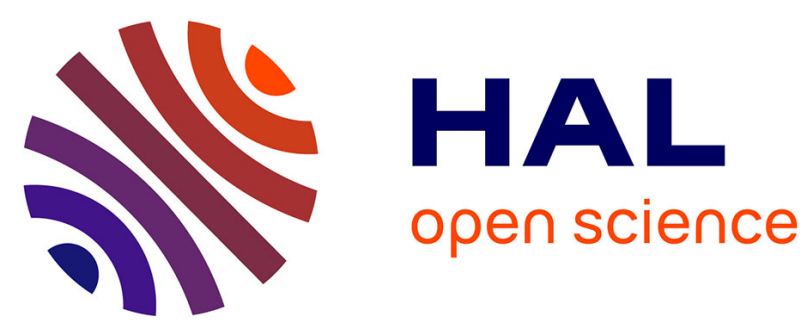

\title{
Enhanced Performance Love Wave Magnetic Field Sensors with Temperature Compensation
}

Yang Yang, Harshad Mishra, Prince Mengue, Sami Hage-Ali, S. Petit-Watelot, Daniel Lacour, Hamid M'Jahed, Michel Hehn, Tao Han, Omar Elmazria

\section{- To cite this version:}

Yang Yang, Harshad Mishra, Prince Mengue, Sami Hage-Ali, S. Petit-Watelot, et al.. Enhanced Performance Love Wave Magnetic Field Sensors with Temperature Compensation. IEEE Sensors Journal, 2020, pp.1-1. 10.1109/JSEN.2020.2998826 . hal-02865483

\section{HAL Id: hal-02865483 https://hal.science/hal-02865483}

Submitted on 11 Jun 2020

HAL is a multi-disciplinary open access archive for the deposit and dissemination of scientific research documents, whether they are published or not. The documents may come from teaching and research institutions in France or abroad, or from public or private research centers.
L'archive ouverte pluridisciplinaire HAL, est destinée au dépôt et à la diffusion de documents scientifiques de niveau recherche, publiés ou non, émanant des établissements d'enseignement et de recherche français ou étrangers, des laboratoires publics ou privés. 


\title{
Enhanced Performance Love Wave Magnetic Field Sensors with Temperature Compensation
}

\author{
Yang Yang, Harshad Mishra, Prince Mengue, Sami Hage-Ali, Member, IEEE, Sébastien Petit-Watelot, Daniel Lacour, \\ Michel Hehn, Hamid M'Jahed, Tao Han*, Member, IEEE, and Omar Elmazria*, Senior Member, IEEE
}

\begin{abstract}
Temperature compensation is critical and important for surface acoustic wave (SAW) magnetic field sensors. In this study, a Love wave mode based SAW device is investigated as a magnetic field sensor. The considered structure is composed of a $\mathrm{CoFeB}$ magnetostrictive film as sensitive layer, $\mathrm{SiO}_{2}$, and $\mathrm{ZnO}$ film as insulating and temperature compensation layers and $\mathrm{ST}+90^{\circ}$-cut quartz as substrate. A theoretical model is proposed to study the magnetic field sensitivity and temperature coefficient of frequency (TCF) variations. Optimized structures by calculation were fabricated and characterized and obtained results show a good agreement between experiments and our model simulation. We clearly shown that signal performances as well as the flexibility of the resonator design were improved by adding the isolating $\mathrm{SiO}_{2}$ layer. Thus, a sensor showing a near zero TCF $\left(0.1 \mathrm{ppm} /{ }^{\circ} \mathrm{C}\right)$ and a magnetic field sensitivity of $-\mathbf{4 2 0} \mathrm{ppm} / \mathrm{mT}$ was achieved with the structure $\mathrm{CoFeB}(100 \mathrm{~nm}) / \mathrm{SiO}_{2}(250 \mathrm{~nm}) / \mathrm{ZnO}(300 \mathrm{~nm}) /$ Quartz $\left(\mathrm{ST}-\mathrm{X}+90^{\circ}\right)$. This multi-layered structure is beneficial to design reliable SAW magnetic field sensors.
\end{abstract}

Index Terms- Love wave resonator; magnetostriction; magnetic field sensor; temperature compensation;

\section{INTRODUCTION}

Magnetostrictive materials are widely applied in the areas of sensors and actuators owing to their ability to transduce between the magnetic and mechanical energy [1]-[3]. Surface acoustic wave (SAW) devices based on magnetostrictive films have been extensively studied for the development of magnetic field sensors, current sensors, and tunable SAW filters [4]-[9]. The frequency of the SAW resonator is sensitive to the applied surface strain, stress, and the changes of elastic constants. The magnetostriction effect and $\Delta \mathrm{E}$ effect are intrinsic properties of magnetostrictive materials. On the

Manuscript received, 2020. This research was supported by the National Key Research and Development Program of China (2016YFB0402700), National Natural Science Foundation of China (under grant No. U1837210, No.11774230 and No.61531008), Key Research and Development Program of Jiangsu Province (Grant No. BE2018008-5), and the French PIA project "Lorraine Université d'Excellence" (ANR-15-IDEX-04-LUE) and ANR JCJC SAWGOOD (ANR-18-CE42-0004-01). (*Corresponding author: Tao Han, Omar Elmazria.)

Yang Yang, and Tao Han are with the School of Electronic Information and Electrical Engineering, Shanghai Jiao Tong University, Shanghai 200240, China. (e-mail: yangyang2015@sjtu.edu.cn; than@ sjtu.edu.cn)

Harshad Mishra, Prince Mengue, Sami Hage-Ali, Sébastien Petit-Watelot, Daniel Lacour, Michel Hehn, Hamid M'Jahed, and Omar Elmazria are with the Institute Jean Lamour UMR 7198, Université de Lorraine - CNRS, Nancy,54000,France.(e-mail:harshad.vr1@gmail.com; omar.elmazria@univlorraine.fr) one hand, magnetostriction effect generates magnetostrictive strain and stress when an external magnetic field is applied; On the other hand, the elastic constants of magnetostrictive materials change dependent on the applied magnetic field $(\Delta \mathrm{E}$ effect), thus affecting the resonance frequency. In previous reported studies, a lot of efforts have been made towards the development of reliable SAW based magnetic field sensors with different magnetostrictive materials, such as Nickel (Ni), Terbium-Iron ( $\left.\mathrm{TbFe}_{2}\right)$, Iron-Cobalt (FeCo), Galfenol (FeGa), and Metglas (FeCoSiB) [10]-[15]. A magnetic field sensitivity of $2.17 \mathrm{ppm} / \mathrm{mT}$ was obtained by Kadota et al. on a Ni/quartz structure [10]. A SAW velocity change of $-0.27 \%$ at the field of $400 \mathrm{mT}$ was achieved by Yamaguchi et al. in a delay line consisting of an amorphous $\mathrm{TbFe}_{2}$ film [11]. An FeCo coated sensor with the sensitivity of $17.72 \mathrm{kHz} / \mathrm{mT}$ was developed at $300 \mathrm{MHz}$ by Wang et al. [12]. Smole et al. obtained a frequency variation of $-1.21 \%$ for the magnetically tunable SAW resonator at $1.2 \mathrm{GHz}$ with the applied magnetic field between 0 and $5 \mathrm{mT}$ [13]. A maximum velocity change of $0.64 \%$ was obtained on a SAW delay line by Li et al. using a $500 \mathrm{~nm}$ thick FeGa thin film with the coercivity [14]. A measured phase change of $300^{\circ}$ is achieved from 0 to $2 \mathrm{mT}$ on a delay line structure with a $200 \mathrm{~nm}$ thick FeCoSiB film by Kittmann et al. [15]. As noted in these research work, the properties of magnetostrictive films play crucial roles. Moreover, the environment temperature is a factor affecting the performance of SAW sensors [16]. Thermal expansions and material constants dependent on temperatures affect the resonance frequency of SAW resonators. An unavoidable fact is that the SAW magnetic field sensors without temperature compensation are sensitive to both magnetic field and temperature. The changes of temperature will cause the frequency drifts of sensors [17]. Therefore, a SAW magnetic field sensor with a high sensitivity and a zero temperature coefficient of frequency (TCF) is essential for applications.

One-port Love wave mode resonators have the potential of being wireless sensing platforms for measuring magnetic field. On the one hand, the wave-guiding layer of a Love wave mode resonator can protect the interdigital transducers (IDTs) and reflector gratings naturally; On the other hand, the magnetostrictive thin film is deposited directly on the waveguiding layer as sensitive medium that enhances the sensing areas and thus improves the sensitivity to the magnetic field [18]. However, the frequency variation of a Love wave 
magnetic sensor caused by the environmental temperature is a critical factor that affects the measurement accuracy. Thus, temperature compensated structures for the zero TCF along with a large magnetic field sensitivity attract much attention.

In this work, a theoretical model is proposed to study the sensitivity of SAW resonance frequency to a magnetic field. The model also describes the frequency-temperature characteristics. The model is validated by the study of a $\mathrm{CoFeB} / \mathrm{ZnO} /$ quartz Love wave based structure. Thereafter, a proposal is made to develop a new structure based on $\mathrm{CoFeB} / \mathrm{SiO}_{2} / \mathrm{ZnO} / q u a r t z$. This later structure allows more flexibility of film thickness choice and is more suitable to operate at high frequencies in $\mathrm{MHz}$ range. The $\mathrm{ZnO}$ and $\mathrm{CoFeB}$ have negative temperature coefficients. However, $\mathrm{SiO}_{2}$ has positive temperature coefficients. The temperature coefficient of frequency (TCF) of $\mathrm{ST}+90^{\circ}$-cut quartz is also positive. Therefore, the temperature compensation is realized due to the combination of $\mathrm{ST}+90^{\circ}$-cut quartz, $\mathrm{ZnO}, \mathrm{SiO}_{2}$, and $\mathrm{CoFeB}$ films. The $\mathrm{S}_{11}$ response and magnetic field sensitivity of the sensor are improved. Finally, the accuracy of the model for the magnetic field sensitivity is validated by experiments.

The remaining of paper is as follows: In section II, a model analysis for the SAW magnetic field devices in an externally applied magnetic field is investigated. In section III, the model is verified in experiments, and the magnetic field sensitivities of the Love wave mode magnetic field resonators are studied. Conclusions are discussed in section IV.

\section{THEORETICAL MODEL}

A three-dimensional model of a magnetostrictive film/isolating layers/IDT/quartz multi-layered structure is established in the finite element analysis. The magnetic field, solid mechanical field, and static electric field are added into the model. The magnetostrictive effect with geometry deformation is considered with the coupling of the magnetic field and the mechanical field. The magnetostrictive CoFeB film converts the applied external magnetic field into mechanical perturbations that disturbs the acoustic wave velocity. The magnetic mechanical coupling model is based on the perturbation theory and is expressed in Lagrange description.

The deformation is related to the magnetization rotation towards the direction of the applied magnetic field. During this rotation, the magnetostrictive strain of the $\mathrm{CoFeB}$ film due to the magnetostriction effect is defined as follows:

$$
\sigma=\frac{1}{M_{s}^{2}}\left[\begin{array}{lll}
\lambda_{100}\left(M_{x}^{2}-\frac{M_{y}^{2}+M_{z}^{2}}{2}\right) & \frac{3}{2} \lambda_{111} M_{x} M_{y} & \frac{3}{2} \lambda_{111} M_{x} M_{z} \\
\frac{3}{2} \lambda_{111} M_{x} M_{y} & \lambda_{100}\left(M_{y}^{2}-\frac{M_{x}^{2}+M_{z}^{2}}{2}\right) & \frac{3}{2} \lambda_{111} M_{y} M_{z} \\
\frac{3}{2} \lambda_{111} M_{x} M_{z} & \frac{3}{2} \lambda_{111} M_{y} M_{z} & \lambda_{100}\left(M_{z}^{2}-\frac{M_{x}^{2}+M_{y}^{2}}{2}\right)
\end{array}\right]
$$

where $\lambda_{100}$ and $\lambda_{111}$ are magnetostrictive coefficients. For $\mathrm{CoFeB}, \lambda_{100}=139 \mathrm{ppm}, \lambda_{111}=22 \mathrm{ppm}$ [19]. The $100 \mathrm{~nm} \mathrm{CoFeB}$ film deposited at a high sputtering power in experiments is magnetic anisotropic and has a polycrystalline lattice structure.
$M_{s}$ is the saturation magnetization. $M_{x}, M_{y}$, and $M_{z}$ are the magnetization components along $\mathrm{X}, \mathrm{Y}$, and $\mathrm{Z}$ directions. When a magnetic field is applied parallel to the hard axis, the changes of elastic constant due to $\Delta \mathrm{E}$ effect as a function of the magnetic field are defined as follows [20]:

$$
\begin{gathered}
\Delta C_{11}=\left\{\begin{array}{cc}
-\frac{b^{2}\left(\frac{H^{2}}{H_{s}^{2}}\right)}{\mu_{0} M_{s}\left(H+H_{s}+H_{m e}\right)} & \left(H \leq H_{s}\right) \\
0 & \left(H>H_{s}\right)
\end{array}\right. \\
\Delta C_{66}= \begin{cases}-\frac{b^{2}\left(1-2 \frac{H^{2}}{H_{s}^{2}}\right)}{\mu_{0} M_{s}\left(H+H_{s}\left(1-2 \frac{H^{2}}{H_{s}{ }^{2}}\right)+H_{m e}\right)} & \left(H \leq H_{s}\right) \\
-\frac{b^{2}}{\mu_{0} M_{s}\left(H-H_{s}+H_{m e}\right)} & \left(H>H_{s}\right)\end{cases}
\end{gathered}
$$

where $H$ is the external applied magnetic field. $H_{s}$ is the saturation field. $H_{m e}$ represents the magneto-elastic field. $b$ is the magneto-elastic coefficient. $\mu_{0}$ is a vacuum permeability. It can be found that the changes of elastic constants are dependent on the magneto-elastic coefficient and the saturation magnetization. Rayleigh wave is mainly sensitive to $\mathrm{C}_{11}$ of the magnetostrictive film. Love wave is mainly sensitive to $\mathrm{C}_{66}$ of the magnetostrictive film.

The magnetostrictive stresses and strains are superimposed to the surface acoustic wave motion. The fundamental elastic and piezoelectric constants are replaced by the effective material constants dependent on the stress and strain biasing. The third-order elastic constants are imported into the effective material constants. Strain tensors and geometry deformation are calculated at the applied magnetic field using the stationary analysis. For the piezoelectric film and the substrate, the effective elastic constants $c_{L \gamma M \alpha}$, piezoelectric constants $e_{M L \gamma}$, dielectric constants $\varepsilon_{L M}$ are defined as follows [21]:

$$
\begin{aligned}
& c_{L \gamma M \alpha}=c_{L \gamma M \alpha}^{0}+T_{L M}^{0} \delta_{\gamma \alpha}+c_{L \gamma M \alpha A B} S_{A B}^{0}+c_{L K M \alpha}^{0} w_{\gamma, K}+c_{L \gamma K M}^{0} w_{\alpha, K} \\
& e_{M L \gamma}=e_{M L \gamma}^{0}+e_{M L \gamma A B} S_{A B}^{0}+e_{M L K}^{0} w_{\gamma, k}+X_{A M L \gamma} E_{A}^{0} \\
& \varepsilon_{L M}=\varepsilon_{L M}^{0}+X_{L M A B} S_{A B}^{0}+\varepsilon_{L M k} E_{k}^{0}
\end{aligned}
$$

where $c^{0}{ }_{L \gamma M \alpha}, e^{0}{ }_{M L \gamma}$, and $\varepsilon_{L M}^{0}$ are the fundamental elastic, piezoelectric, and dielectric constants, respectively. $T^{0}{ }_{L M}$ denotes the stress generated by the magnetostrictive film. $\delta_{\gamma \alpha}$ is a Kronecker delta. $S_{A B}^{0}, E_{A}^{0}$ and $w_{\gamma, K}$ are the initial strain, electrical field and deformation gradient caused by the magnetostriction effect, respectively. $X_{A M L \gamma}$ is the electrostrictive constant. $c_{L \gamma M \alpha A B}, e_{M L \gamma A B}$, and $\varepsilon_{L M k}$ are the thirdorder elastic, piezoelectric, and dielectric constants, respectively. In the analysis, the electrical boundary condition for the $\mathrm{ZnO}$ and $\mathrm{SiO}_{2}$ top surface is the charge conservation condition. The wave propagation is solved based on the simultaneous solution of the nonlinear constitutive equations and the motion equation. The magnetic field sensitivity is defined as follows:

$$
S_{\text {mag }}=\frac{\Delta f}{f_{0} \Delta H}=\frac{1}{f_{0}} \frac{d f}{d H}
$$


where $f_{0}$ is the resonance frequency at the zero magnetic field, and $\Delta f$ is the frequency shift when the magnetic field changes $\Delta H$.

The frequency-temperature characteristic of the SAW magnetic field sensor is calculated using the prestress analysis based on the nonlinear thermomechanical coupling model [18]. The effective material constants under a thermal biasing field are defined by:

$$
\begin{aligned}
& c_{L \gamma M \alpha}=c_{L \gamma M \alpha}^{0}+c_{L \gamma M \alpha}^{1} \Delta \Theta+c_{L \gamma M \alpha A B}^{0} S_{A B}^{\Theta}+c_{L K M \alpha}^{0} w_{\gamma, K}^{\Theta}+c_{L \gamma K M}^{0} w_{\alpha, K}^{\Theta} \\
& e_{i j}=e_{i j}^{0}+e_{i j}^{1} \Delta \Theta+e_{i j k}^{0} S_{k}^{\Theta}+e_{i j}^{0} w^{\Theta} \\
& \varepsilon_{i j}=\varepsilon_{i j}^{0}+\varepsilon_{i j}^{1} \Delta \Theta+\varepsilon_{i j k}^{0} E_{k}
\end{aligned}
$$$$
\text { where } c_{L \gamma M \alpha}^{1}, e_{i j}^{1} \text {, and } \varepsilon_{i j}^{1} \text { are the first-order temperature }
$$
derivatives of the fundamental elastic constants, piezoelectric constants, and dielectric constants, respectively. $\Delta \Theta$ is the changes of the temperature. $S_{k}^{\Theta}, w^{\Theta}$, and $E_{k}$ are the thermal strain, displacement gradient, and initial electrical field. The temperature coefficient of frequency (TCF) is calculated as follows:

$$
T C F=\frac{f_{\Theta}-f_{\Theta_{0}}}{f_{\Theta_{0}}\left(\Theta-\Theta_{0}\right)}
$$

where $f_{\Theta_{0}}$ is the resonance frequency at the reference temperature $\Theta_{0}$, and $f_{\Theta}$ is the resonance frequency at the given temperature $\Theta$.

\section{EXPERIMENTS AND DISCUSSION}

\section{A. Model validation with the CoFeB/ZnO/quartz structure}

Using photolithography and a lift-off based fabrication process, synchronous one-port Love wave mode resonators were fabricated for $\mathrm{ZnO} / \mathrm{ST}+90^{\circ}$-cut quartz structure. Interdigital transducers (IDTs) were patterned in the interface $\mathrm{ZnO} /$ quartz. The thickness of the $\mathrm{Al}$ electrode was $100 \mathrm{~nm}$. The wavelength was set to $10 \mu \mathrm{m}$ and will be considered for all devices studied in this paper. This value allows a direct and simple calculation of velocity from frequency values that are expressed in MHz. The metallization ratio is 0.5. Fig. 1 shows the variation of resonance frequency of the Love wave mode in the $\mathrm{ZnO} / \mathrm{ST}+90^{\circ}$-cut quartz resonator versus temperatures and for various thicknesses of $\mathrm{ZnO}$ layers. The dotted lines in Fig. 1 are the experimental data, and the solid lines are the calculated results. The experimental results for the $0 \mathrm{~nm} \mathrm{ZnO}$ and $510 \mathrm{~nm} \mathrm{ZnO}$ are adapted from Ref. [17]. Here, more samples with other thicknesses were measured and calculated to verify the accuracy of the model. We can note the good agreement obtained between experimentally measured data and calculated ones using our numerical model. Experimental and calculated TCF values were then determined from theses curves and reported in Fig. 2, that shows the evolution of TCF versus $\mathrm{ZnO}$ film thickness. The $\mathrm{ZnO}$ thickness $\left(\mathrm{h}_{\mathrm{ZnO}}\right)$ is normalized by the wavelength value $(\lambda=10 \mu \mathrm{m})$. We can note that the zero TCF is obtained when the $\mathrm{ZnO}$ thickness is around $500 \mathrm{~nm}$. The TCF of the structure is positive for $\mathrm{ZnO}$ thickness lower than $500 \mathrm{~nm}(+19.7$ $\mathrm{ppm} /{ }^{\circ} \mathrm{C}$ for $\left.200 \mathrm{~nm}\right)$ and negative for thicker films $(-4.89$ $\mathrm{ppm} /{ }^{\circ} \mathrm{C}$ for $600 \mathrm{~nm}$ ). The device achieved with $510 \mathrm{~nm}$ thick of $\mathrm{ZnO}$ shows a TCF value that is as expected close to zero and could be adjusted by decreasing slightly the $\mathrm{ZnO}$ film thickness. Note that the real value measured with a profilometer on this device was $510 \mathrm{~nm}$ and not $500 \mathrm{~nm}$. This result is then consistent with measured TCF value.

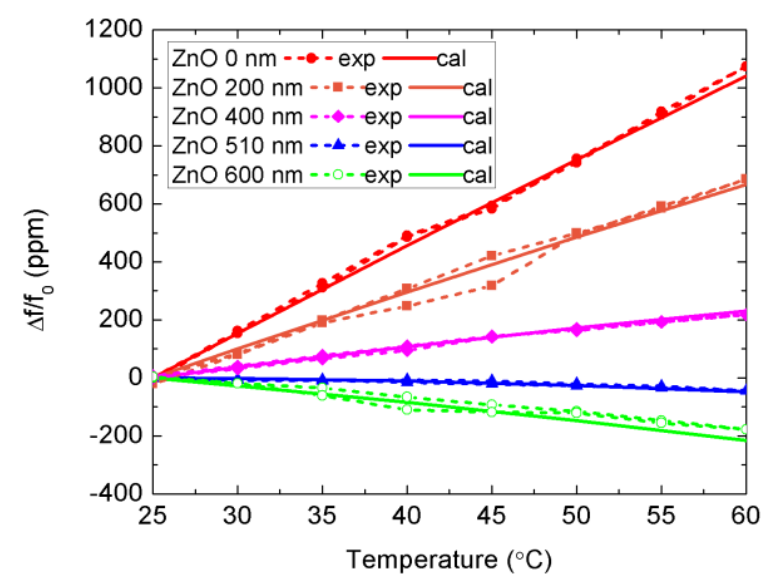

Fig. 1. The calculated and experimental frequency-temperature curves of Love wave mode on $\mathrm{ZnO} / \mathrm{ST}+90^{\circ}$-cut quartz as a function of $\mathrm{ZnO}$ thicknesses. The wavelength is $10 \mu \mathrm{m}$. The dotted lines are the experimental data (exp), and the solid lines are the calculated data (cal).

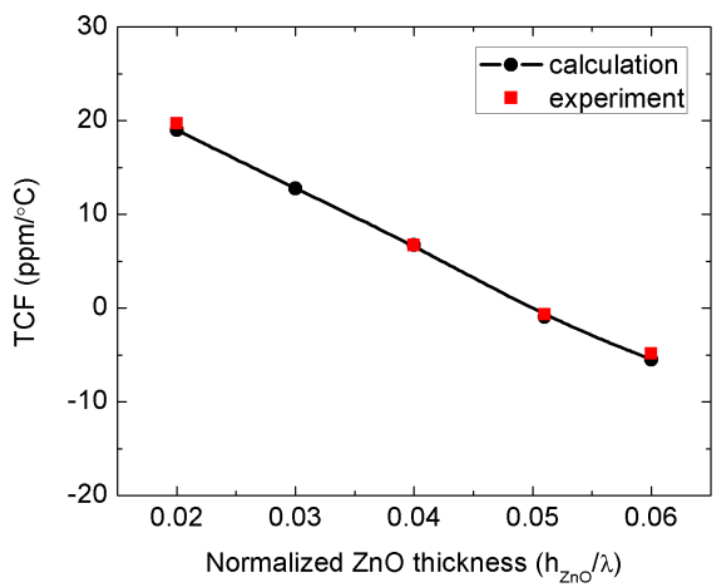

Fig. 2. The TCF variations of Love wave mode on $\mathrm{ZnO} / \mathrm{ST}+90^{\circ}$-cut quartz as a function of $\mathrm{ZnO}$ thicknesses $\left(\mathrm{h}_{\mathrm{ZnO}}\right)$ normalized by the wavelength. The wavelength $(\lambda)$ is $10 \mu \mathrm{m}$.

The magnetostrictive $\mathrm{CoFeB}$ thin film is used as the sensitive medium for magnetic field sensing. Using magnetron sputtering technology, one-port Love wave mode resonators with $\mathrm{CoFeB} / \mathrm{ZnO} / \mathrm{ST}+90^{\circ}$-cut quartz structure were fabricated, as shown in Fig. 3. $100 \mathrm{~nm}$ thick $\mathrm{CoFeB}$ was deposited over $\mathrm{ZnO} / \mathrm{ST}+90^{\circ}$-cut quartz by $\mathrm{DC}$ magnetron sputtering at $300 \mathrm{~W}$ with $5 \times 10^{-3}$ mbar pressure of argon (Ar). 


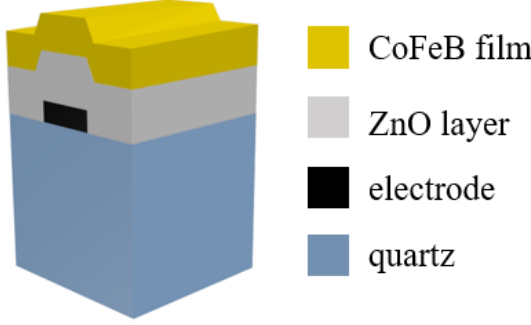

Fig. 3. The schematic of the $\mathrm{CoFeB} / \mathrm{ZnO} / q u a r t z$ multi-layered structure.

In the fabrication, a bias magnetic field was used to control the easy and hard axes of the CoFeB film specifically with respect to substrate coordinates. The easy axis is parallel to the aperture direction and perpendicular to the Love wave propagation. The hard axis is perpendicular to the aperture direction and parallel to the Love wave propagation. Vibrating sample magnetometer (VSM) measurements were performed to get the magnetization of $\mathrm{CoFeB}$ thin films. Fig. 4 presents the anisotropy axis magnetization measured on a $100 \mathrm{~nm}$ $\mathrm{CoFeB}$ film and $200 \mathrm{~nm} \mathrm{CoFeB}$ film at the room temperature. The advantage of using $\mathrm{CoFeB}$ lies in its low saturation field along the hard axis. The magnetostrictive layer with a higher thickness has a larger mass. Love waves are sensitive to the mass loading. When the thickness of the magnetostrictive film increases, more energy of the Love wave mode is concentrated in the magnetostrictive film according to the displacement distributions. Therefore, it is understandable that a higher thickness of the magnetostrictive layer would imply a higher sensitivity. However, due to the thickness-driven spinreorientation transition [22], the magnetic properties of $\mathrm{CoFeB}$ films are related to the thicknesses [23]. The $100 \mathrm{~nm}$ thick $\mathrm{CoFeB}$ film exhibits in-plane magnetic anisotropy that causes the magnetization to be parallel to the film plane. Our experimental analysis revealed that increasing the thickness to $200 \mathrm{~nm}$ resulted in an in-plane isotropic magnetic behavior. Upon increasing the thickness of a CoFeB film, the redistribution of accumulated internal stress in the film induced by the deposition increases the degree of local disorder in the easy axis and increases the coercive field [23]. Furthermore, the coercive field is $0.18 \mathrm{mT}$ along the hard axis when the CoFeB film is $100 \mathrm{~nm}$. Nevertheless, the coercive field increases a lot to $3 \mathrm{mT}$ along the hard axis when the $\mathrm{CoFeB}$ film is $200 \mathrm{~nm}$. Hence, in order to give our device a good directionality and a low coercive field, we chose to work with a thickness of $100 \mathrm{~nm}$ of the $\mathrm{CoFeB}$ layer.
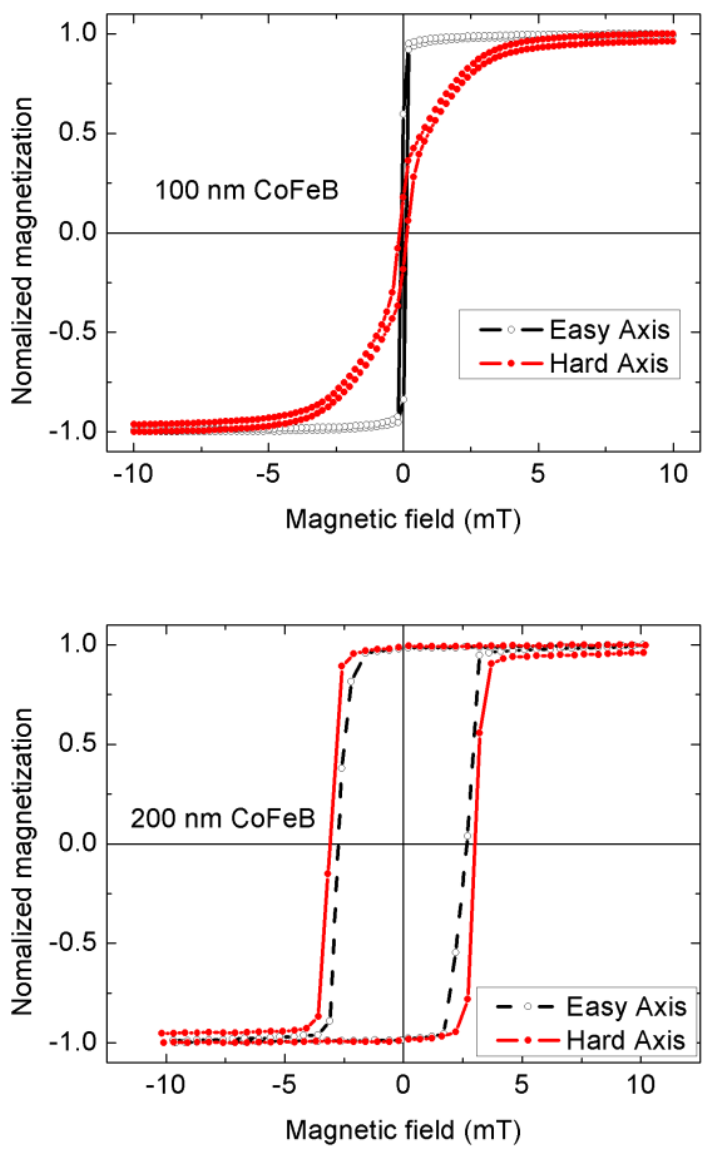

Fig. 4. The measured magnetizations of the $100 \mathrm{~nm}$ and $200 \mathrm{~nm} \mathrm{CoFeB}$ films.

Fig. 5 illustrates the calculated frequency-temperature characteristics of Love wave mode on $\mathrm{CoFeB} / \mathrm{ZnO} / \mathrm{ST}+90^{\circ}$ cut quartz versus different $\mathrm{ZnO}$ thicknesses. $\mathrm{CoFeB}$ film thickness is fixed to $100 \mathrm{~nm}$. The dotted lines are the experimental data adapted from Ref. [17]. It is found that the $\mathrm{CoFeB}$ film has negative temperature coefficients. Indeed, when the $100 \mathrm{~nm} \mathrm{CoFeB}$ film is deposited on the $510 \mathrm{~nm}$ of $\mathrm{ZnO}$ layer, the $\mathrm{TCF}$ value decreases to $-14.6 \mathrm{ppm} /{ }^{\circ} \mathrm{C}$. The structure achieved with $200 \mathrm{~nm}$ of $\mathrm{ZnO}$ shows a near zero TCF $\left(+1.77 \mathrm{ppm} /{ }^{\circ} \mathrm{C}\right)$ and will be considered for next experiment. According to the experimental frequency-temperature data, the temperature coefficients of the $\mathrm{CoFeB}$ film are extracted as follows: $\mathrm{Tc}_{11}=-5.3 \times 10^{-4} /{ }^{\circ} \mathrm{C}, \mathrm{Tc}_{12}=-3.1 \times 10^{-4} /{ }^{\circ} \mathrm{C}, \mathrm{Tc}_{66}=-$ $1.09 \times 10^{-4} /{ }^{\circ} \mathrm{C}$. The solid lines are the calculated results. It can be seen that the calculated results relatively agree with the experimental data. Incertitude observed in experimental curves is mainly due to the weak signal quality and especially for the device with $200 \mathrm{~nm} \mathrm{ZnO}$. Thus, fitted parameters will be considered in the next of this study to optimize high performances sensor.

The TCF evolution with $\mathrm{ZnO}$ film thickness of Love wave mode for $\mathrm{CoFeB} / \mathrm{ZnO} / \mathrm{ST}+90^{\circ}$-cut quartz is illustrated in Fig. 6 . The $\mathrm{ZnO}$ thickness $\left(\mathrm{h}_{\mathrm{ZnO}}\right)$ is normalized by the wavelength value $(\lambda=10 \mu \mathrm{m})$. Additional points are added in simulation using extracted parameters from experimental characterization. 


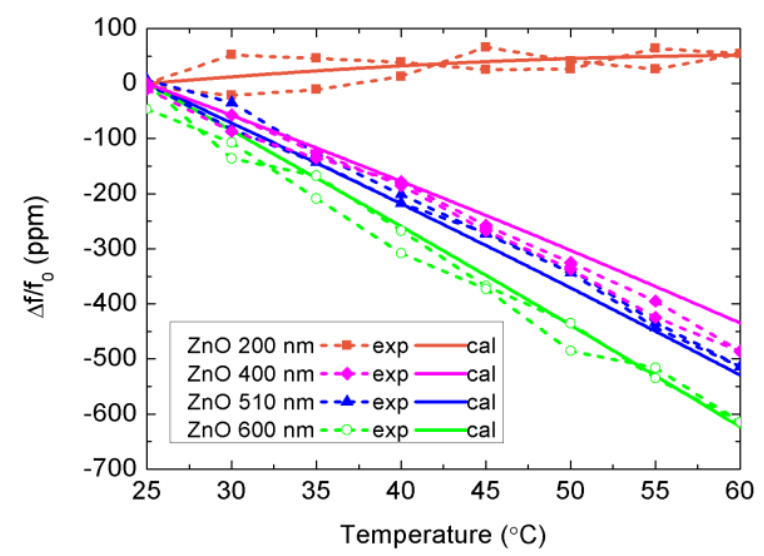

Fig. 5. The calculated and experimental dependence of frequency on temperature for Love wave mode on $\mathrm{CoFeB} / \mathrm{ZnO} / \mathrm{ST}+90^{\circ}$-cut quartz. The dotted lines are the experimental data (exp), and the solid lines are the calculated data (cal)

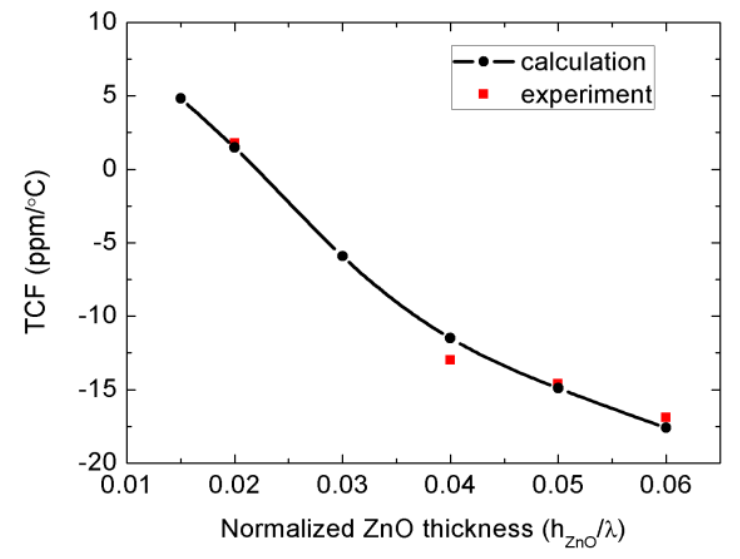

Fig. 6. The calculated and experimental TCF variations of Love wave mode on $\mathrm{CoFeB} / \mathrm{ZnO} / \mathrm{ST}+90^{\circ}$-cut quartz as a function of $\mathrm{ZnO}$ thicknesses $\left(\mathrm{h}_{\mathrm{ZnO}}\right)$ normalized by the wavelength. The wavelength $(\lambda)$ is $10 \mu \mathrm{m}$.

In order to maintain a near zero TCF characteristic, the 100 $\mathrm{nm}$ thick $\mathrm{CoFeB}$ film and $200 \mathrm{~nm} \mathrm{ZnO}$ film are selected for the Love wave sensor in measurements under the magnetic field. The measured $S_{11}$ of the resonators at the room temperature is shown in Fig. 7. The Love wave mode on $\mathrm{ZnO} / \mathrm{ST}+90^{\circ}$-cut quartz operates at $460 \mathrm{MHz}$. After depositing $100 \mathrm{~nm}$ thick $\mathrm{CoFeB}$, the resonance frequency declines to 430 $\mathrm{MHz}$ that was our target to operate in $433 \mathrm{MHz}$ ISM band. However, we can notice a strong degradation of the signal, as shown in Fig. 7(b) [17]. The base line of $S_{11}$ signal is around $-2.85 \mathrm{~dB}$ and the amplitude decreases a lot due to the power loss. This is due to the equivalent capacitance between the $\mathrm{ZnO}$ and $\mathrm{CoFeB}$ layers. Indeed, $\mathrm{CoFeB}$ is conductive, and hence capacitive and inductive losses are very high when the $\mathrm{CoFeB}$ is very close to the IDTs. The performance of the device therefore is affected. A part of the current flows to the $\mathrm{CoFeB}$ film due to the low thickness of the insulator layer $(\mathrm{ZnO})$. When the thickness of $\mathrm{ZnO}$ is set to $600 \mathrm{~nm}$, the amplitude of $S_{11}$ signal is improved as it can be shown in Fig. 7(c) [17]. However, for this structure, the TCF is not compensated and is equal to $-16.9 \mathrm{ppm} /{ }^{\circ} \mathrm{C}$.

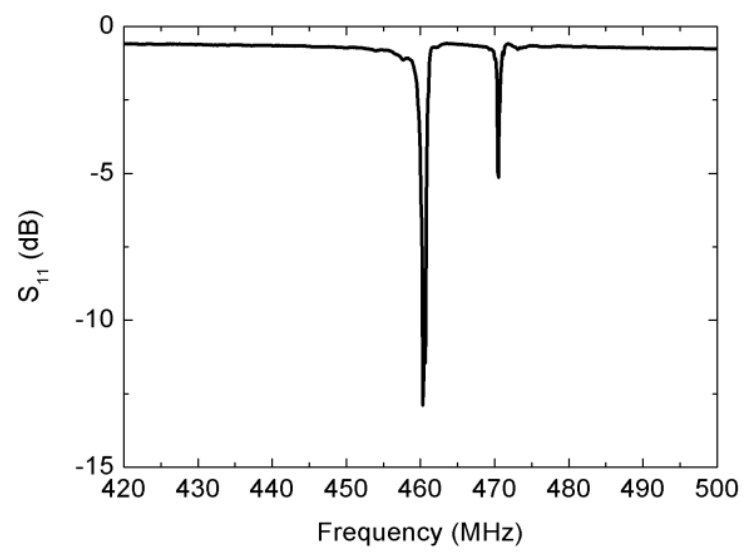

(a)

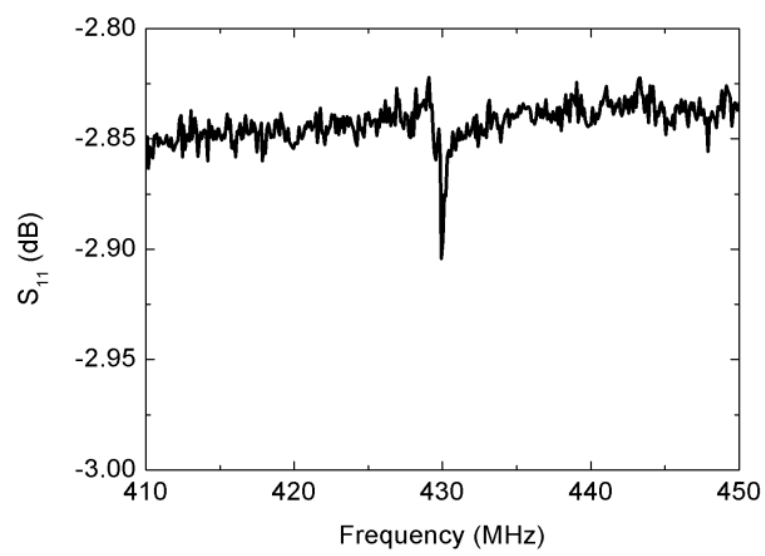

(b)

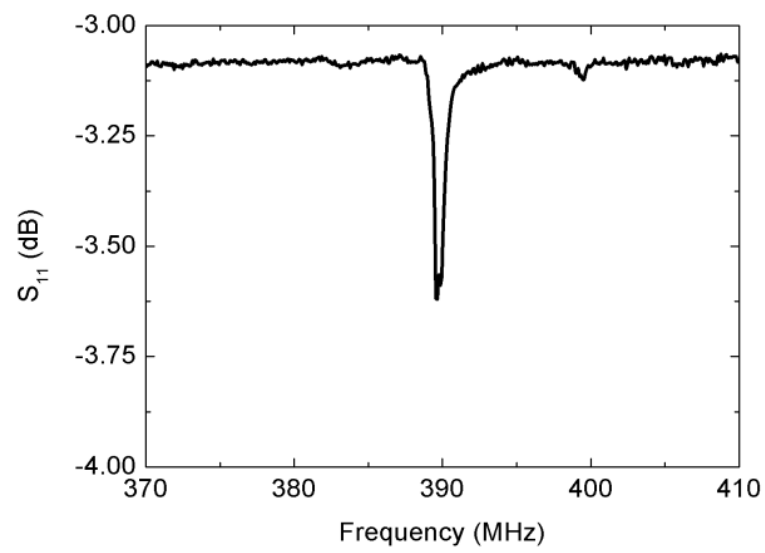

(c)

Fig. 7. (a) The measured $\mathrm{S}_{11}$ of $\mathrm{ZnO} / \mathrm{ST}+90^{\circ}$-cut quartz. The thickness of $\mathrm{ZnO}$ is $200 \mathrm{~nm}$. (b) The measured $\mathrm{S}_{11}$ of $\mathrm{CoFeB} / \mathrm{ZnO} / \mathrm{ST}+90^{\circ}$-cut quartz. The thickness of $\mathrm{CoFeB}$ is $100 \mathrm{~nm}$, and the thickness of $\mathrm{ZnO}$ is $200 \mathrm{~nm}$. (c) The measured $\mathrm{S}_{11}$ of $\mathrm{CoFeB} / \mathrm{ZnO} / \mathrm{ST}+90^{\circ}$-cut quartz. The thickness of $\mathrm{CoFeB}$ is $100 \mathrm{~nm}$, and the thickness of $\mathrm{ZnO}$ is $600 \mathrm{~nm}$.

Fig. 8 illustrates the displacement distributions for the Love wave mode at the resonance frequency on $\mathrm{ZnO} / \mathrm{ST}+90^{\circ}$ cut quartz and $\mathrm{CoFeB} / \mathrm{ZnO} / \mathrm{ST}+90^{\circ}$-cut quartz structures. The thicknesses of the $\mathrm{ZnO}$ films are both fixed at $200 \mathrm{~nm}$. The energy of the Love wave mode is mostly concentrated in the 
top surface, and this concentration is improved by presence of the CoFeB layer.

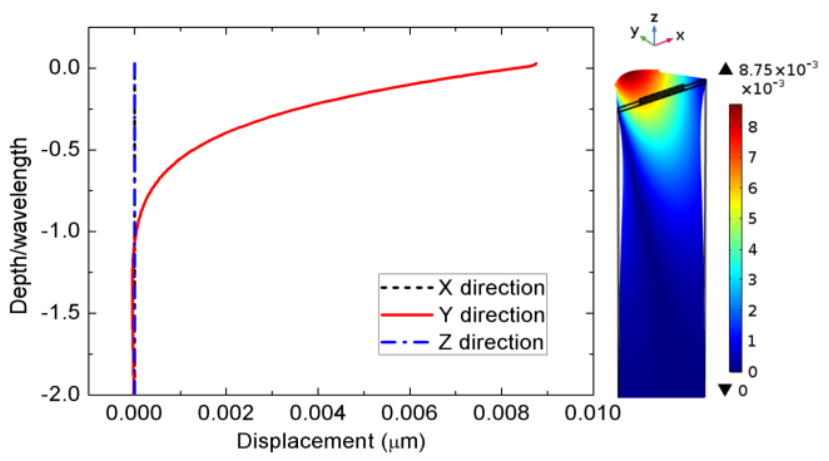

(a)

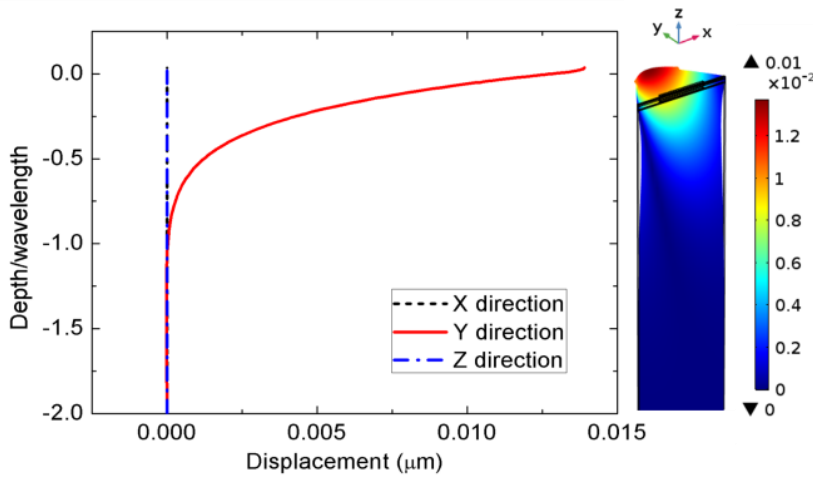

(b)

Fig. 8. (a) The displacement distribution of Love wave mode along the depth of $\mathrm{ZnO} / \mathrm{ST}+90^{\circ}$-cut quartz at the resonance frequency. (b) The displacement distribution of Love wave mode along the depth of $\mathrm{CoFeB} / \mathrm{ZnO} / \mathrm{ST}+90^{\circ}$-cut quartz.

Although the signal amplitude is weak on the $100 \mathrm{~nm}$ $\mathrm{CoFeB} / 200 \mathrm{~nm} \mathrm{ZnO} / \mathrm{quartz}$ resonator, the temperature compensation is obtained. The magnetic field sensitivity of this resonator was characterized under an applied magnetic field. Fig. 9 illustrates the simulation and experimental frequency variations of the Love wave mode as a function of the applied magnetic field that is parallel to the hard axis at the room temperature. The constants of $\mathrm{CoFeB}$ are as follows: Young's modulus $=160 \mathrm{GPa}$, Poisson's ratio $=0.37, b=-3 \times 10^{6}$ $\mathrm{J} / \mathrm{m}^{3}, \mathrm{M}_{\mathrm{s}}=954.9 \mathrm{kA} / \mathrm{m}, \lambda_{100}=139 \mathrm{ppm}, \lambda_{111}=22 \mathrm{ppm}$ [19]. The solid line in Fig. 9 is the simulation result, and the dotted lines are experimental results [17]. The arrows indicate the magnetic field directions. The simulation results match well with the experimental data. The relative variation of the resonance frequency decreases to the minimum of $-541 \mathrm{ppm}$ when the magnetic field increases from 0 to $27 \mathrm{mT}$. The magnetic field sensitivity is $-20 \mathrm{ppm} / \mathrm{mT}$ in this range. Subsequently, the frequency increases when the magnetic field is above $27 \mathrm{mT}$.

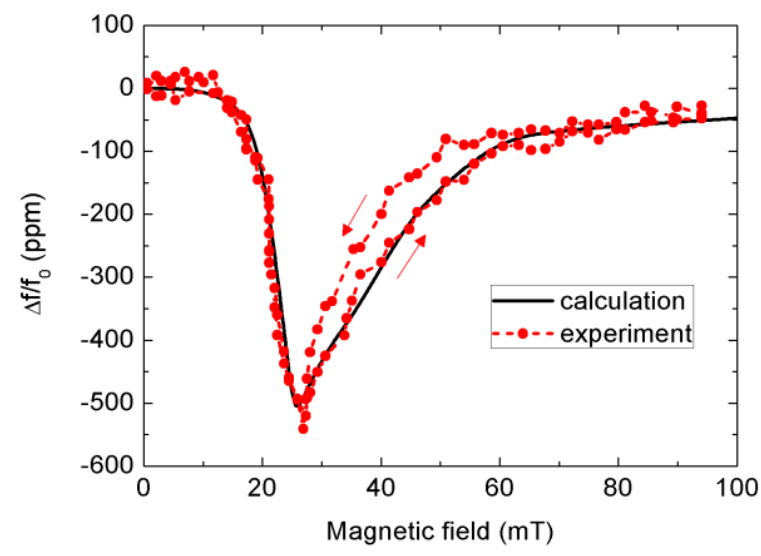

Fig. 9. The calculated and experimental relative frequency shifts of Love wave mode on $\mathrm{CoFeB} / \mathrm{ZnO} / \mathrm{ST}+90^{\circ}$-cut quartz as a function of an applied external magnetic field along the hard axis.

\section{B. $\mathrm{CoFeB} / \mathrm{SiO}_{2} / \mathrm{ZnO} / q u a r t z$ structure}

Our study showed that a zero TCF magnetic field sensor could be achieved with $\mathrm{CoFeB} / \mathrm{ZnO} /$ quartz structure. Our numerical model was validated in comparison with experimental results and will be then used to optimize magnetic field sensors with less thermal drift and with an enhanced magnetic field sensitivity. To improve the signal performance of the sensor and to simultaneously realize a temperature compensation, a $\mathrm{CoFeB} / \mathrm{SiO}_{2} / \mathrm{ZnO} / \mathrm{ST}+90^{\circ}$-cut quartz multi-layered structure is proposed, as shown in Fig. 10. Because the $\mathrm{SiO}_{2}$ has a positive TCF, it can be easily compensated for the negative TCF of the $\mathrm{ZnO}$ and $\mathrm{CoFeB}$ layers. Additionally, because of adding $\mathrm{SiO}_{2}$, we expect to have a higher thickness of $\mathrm{ZnO}$ for a compensated structure with less parasitic capacitance. The $\mathrm{SiO}_{2}$ has a more excellent electrical insulation characteristic than the $\mathrm{ZnO}$. The combination of this structure, therefore would lead to better electrical insulation of the electrodes from the metallic $\mathrm{CoFeB}$ layer and thus a stronger response from the device. The $\mathrm{SiO}_{2}$ layer is proposed to be deposited as an insulating layer between the $\mathrm{CoFeB}$ and the $\mathrm{ZnO}$ layers.

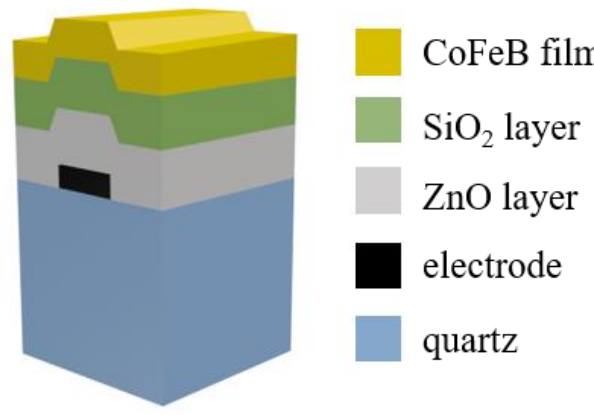

Fig. 10. The schematic of the $\mathrm{CoFeB} / \mathrm{SiO}_{2} / \mathrm{ZnO} /$ quartz multi-layered structure.

The first-order TCF variation of the Love wave mode on the $\mathrm{CoFeB} / \mathrm{SiO}_{2} / \mathrm{ZnO} / \mathrm{ST}+90^{\circ}$-cut quartz is illustrated in Fig. 11 where TCF is calculated versus $\mathrm{SiO}_{2}$ thickness for two thick $\mathrm{ZnO}$ layer (300 $\mathrm{nm}$ and $400 \mathrm{~nm}$ ). The wavelength is $10 \mu \mathrm{m}$. 
The thickness of the CoFeB film is $100 \mathrm{~nm}$. As illustrated in Fig. 11, the near zero TCF is obtained for two combinations of $\mathrm{ZnO}$ and $\mathrm{SiO}_{2}$ thicknesses: $\mathrm{h}_{\mathrm{ZnO}}=300 \mathrm{~nm} ; \mathrm{h}_{\mathrm{SiO} 2}=250 \mathrm{~nm}$ and $\mathrm{h}_{\mathrm{ZnO}}=400 \mathrm{~nm} ; \mathrm{h}_{\mathrm{SiO}_{2}}=400 \mathrm{~nm}$. The couple of $\mathrm{h}_{\mathrm{ZnO}}$ and $\mathrm{h}_{\mathrm{SiO}_{2}}$ will be chosen depending on aimed application. Note that for additional $\mathrm{ZnO}$ thicknesses, new couples of $\mathrm{h}_{\mathrm{ZnO}}$ and $\mathrm{h}_{\mathrm{SiO} 2}$ leading to achieve zero TCF could be obtained. This enable more flexibility to design SAW device when operating frequency is fixed by application aimed. Moreover, in the both cases, the total thickness $\left(\mathrm{h}_{\mathrm{ZnO}}+\mathrm{h}_{\mathrm{SiO}_{2}}\right)$ are respectively $550 \mathrm{~nm}$ and $800 \mathrm{~nm}$. This total thickness is enough to ensure a good electrical isolation between IDTs and the CoFeB layer. Note that thicknesses leading to achieve zero TCF SAW device are proportional to considered wavelength. Thus operating at high frequency will requires thinner film. The combination of $\mathrm{SiO}_{2}$ and $\mathrm{ZnO}$ will be also the choice solution for higher frequency bands.

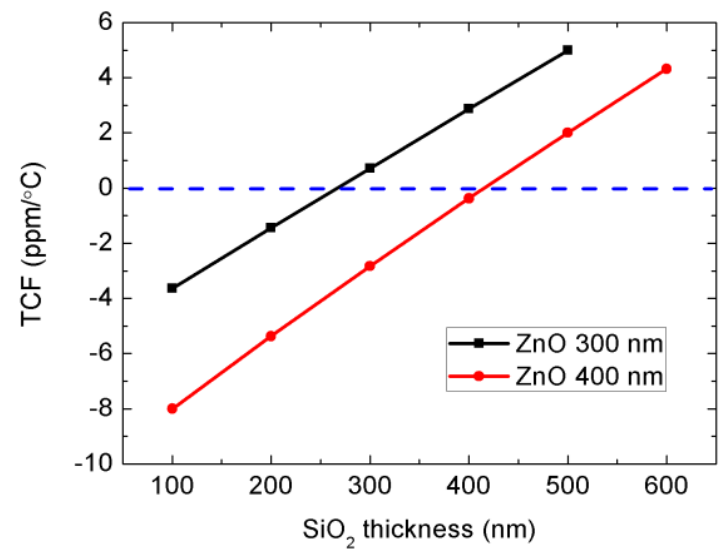

Fig. 11. The TCF variations of Love wave mode on $\mathrm{CoFeB} / \mathrm{SiO}_{2} / \mathrm{ZnO} / \mathrm{ST}+90^{\circ}$ -cut quartz as a function of $\mathrm{SiO}_{2}$ thicknesses.

One-port $\mathrm{CoFeB} / \mathrm{SiO}_{2} / \mathrm{ZnO} / \mathrm{ST}+90^{\circ}$-cut quartz resonators were fabricated using lithography and lift-off process. The 300 $\mathrm{nm} \mathrm{ZnO}$ layer was deposited by RF sputtering at $150 \mathrm{~W}$ with $3 \times 10^{-3} \mathrm{mbar}$ and $8 \mathrm{~cm}^{3} / \mathrm{min}$ flow rate of both argon (Ar) and oxygen $\left(\mathrm{O}_{2}\right)$. Then, $250 \mathrm{~nm} \mathrm{SiO}_{2}$ was deposited on the $\mathrm{ZnO}$ layer by RF sputtering at $100 \mathrm{~W}$ with $4 \times 10^{-3}$ mbar and 8 $\mathrm{cm}^{3} / \mathrm{min}$ flow rate of Ar. The $100 \mathrm{~nm}$ thick CoFeB film was deposited on the top surface of the $\mathrm{SiO}_{2}$ layer by $\mathrm{DC}$ magnetron sputtering of a 2-inch target at $300 \mathrm{~W}$ with $5 \times 10^{-3}$ mbar pressure of Ar. The used apparatus is an ultra-high vacuum equipment "DP 850" from Alliance Concept, Annecy, France. Fig. 12 illustrates the measured frequency-temperature characteristics of Love wave mode on $\mathrm{CoFeB} / \mathrm{SiO}_{2} / \mathrm{ZnO} / \mathrm{ST}+90^{\circ}$-cut quartz and $\mathrm{SiO}_{2} / \mathrm{ZnO} / \mathrm{ST}+90^{\circ}-$ cut quartz. The measured TCF value of $\mathrm{CoFeB} / \mathrm{SiO}_{2} /$ $\mathrm{ZnO} / \mathrm{ST}+90^{\circ}$-cut quartz is $0.1 \mathrm{ppm} /{ }^{\circ} \mathrm{C}$. The temperature compensation is achieved well. The measured $\mathrm{S}_{11}$ of the $\mathrm{CoFeB} / \mathrm{SiO}_{2} / \mathrm{ZnO} / \mathrm{ST}+90^{\circ}$-cut quartz resonator is shown in Fig. 13. The Love wave mode on $\mathrm{CoFeB} / \mathrm{SiO}_{2} / \mathrm{ZnO} / \mathrm{ST}+90^{\circ}-$ cut quartz operates at $409.63 \mathrm{MHz}$. It can be seen that there is little frequency change at $25^{\circ} \mathrm{C}$ and $60{ }^{\circ} \mathrm{C}$. The base line of the $\mathrm{S}_{11}$ signal is around $-2.6 \mathrm{~dB}$. The $\mathrm{S}_{11}$ signal quality is improved and more reliable than those in Fig. 7 (b) and (c) due to the $\mathrm{SiO}_{2}$ layer with a good electrical isolation.

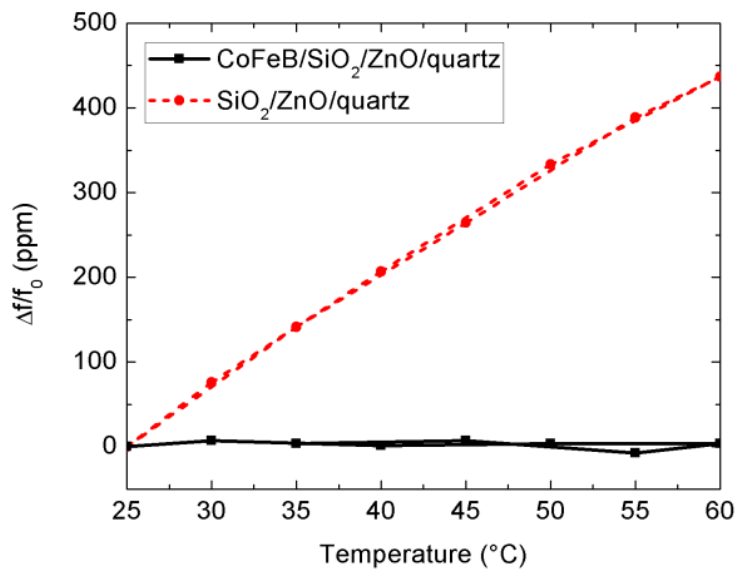

Fig. 12. The measured frequency-temperature characteristics of Love wave mode on $\mathrm{CoFeB} / \mathrm{SiO}_{2} / \mathrm{ZnO} / \mathrm{ST}+90^{\circ}$-cut quartz and $\mathrm{SiO}_{2} / \mathrm{ZnO} / \mathrm{ST}+90^{\circ}$-cut quartz.

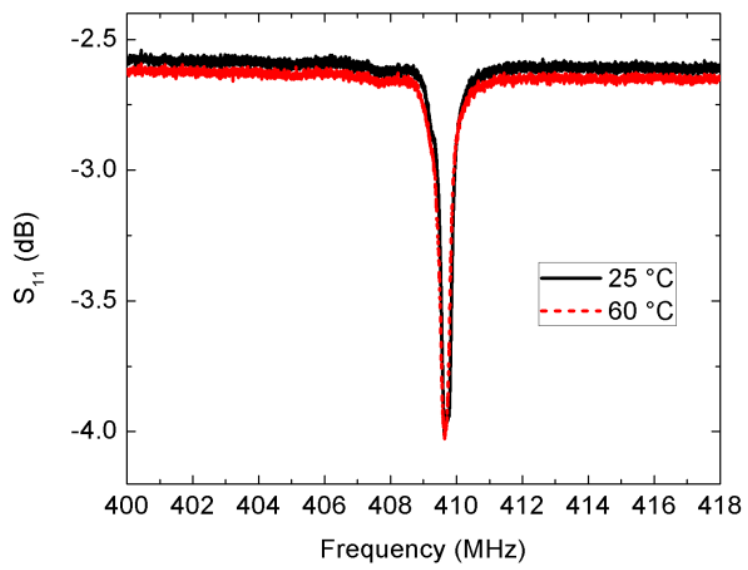

Fig. 13. The measured $\mathrm{S}_{11}$ of $\mathrm{CoFeB} / \mathrm{SiO}_{2} / \mathrm{ZnO} / \mathrm{ST}+90^{\circ}$-cut quartz.

The displacement distribution for the Love wave mode at the resonance frequency on $\mathrm{CoFeB} / \mathrm{SiO}_{2} / \mathrm{ZnO} / \mathrm{ST}+90^{\circ}$-cut quartz is shown in Fig. 14. The $\mathrm{ZnO}$ thickness is $300 \mathrm{~nm}$, and $\mathrm{SiO}_{2}$ thickness is $250 \mathrm{~nm}$. It is found that the most of the energy of the SH component is concentrated in the top surface, and the concentration is improved by adding $\mathrm{SiO}_{2}$ layer compared to the displacement distribution in Fig. 8(b).

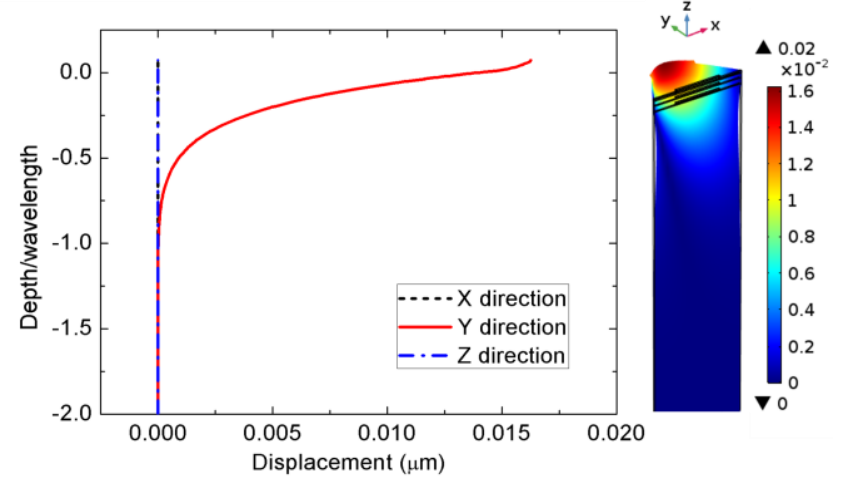

Fig. 14. The displacement distribution of Love wave mode along the depth of $\mathrm{CoFeB} / \mathrm{SiO}_{2} / \mathrm{ZnO} / \mathrm{ST}+90^{\circ}$-cut quartz. 
Fig. 15 illustrates the frequency variations of the Love wave mode on $\mathrm{CoFeB} / \mathrm{SiO}_{2} / \mathrm{ZnO} / \mathrm{ST}+90^{\circ}$-cut quartz as a function of the applied magnetic field along the hard axis at the room temperature. The $\mathrm{ZnO}$ thickness is $300 \mathrm{~nm}$, and $\mathrm{SiO}_{2}$ thickness is $250 \mathrm{~nm}$. The hard axis is parallel to the wave propagation. There is little hysteresis when the magnetic field sweeps from the negative value to the positive value. This hysteresis is probably due to the nature of magnetostrictive layer. Indeed, as shown in Fig. 4, the measured magnetization of $100 \mathrm{~nm} \mathrm{CoFeB}$ shows a weak hysteresis that could be canceled by a micro-structuration of this layer. The relative frequency decreases to $-1597 \mathrm{ppm}$ when the applied magnetic field increases from 0 to $3.8 \mathrm{mT}$. The magnetic field sensitivity of the sensor is $-420 \mathrm{ppm} / \mathrm{mT}$, namely $-172 \mathrm{~Hz} / \mu \mathrm{T}$. It achieves an enhanced magnetic field sensitivity that is more than three

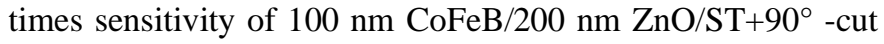
quartz.

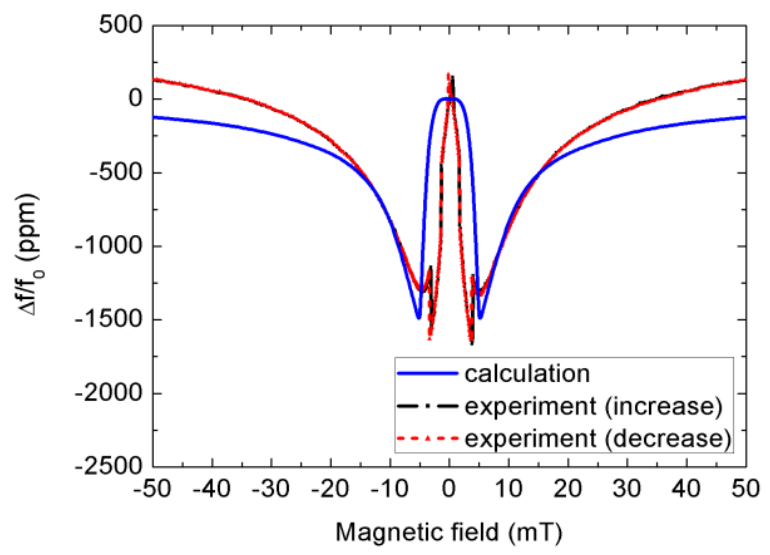

Fig. 15. The relative frequency shifts of Love wave mode on $\mathrm{CoFeB} / \mathrm{SiO}_{2} / \mathrm{ZnO} / \mathrm{ST}+90^{\circ}$-cut quartz as a function of an applied external magnetic field along the hard axis.

Fig. 16 illustrates the $\mathrm{Q}$ variations of the Love wave mode versus the applied magnetic field along the hard axis. Strong variations were recorded between $-10 \mathrm{mT}$ and $10 \mathrm{mT}$. However, the Q factor is almost constant when the magnetic field magnitude is over $20 \mathrm{mT}$.

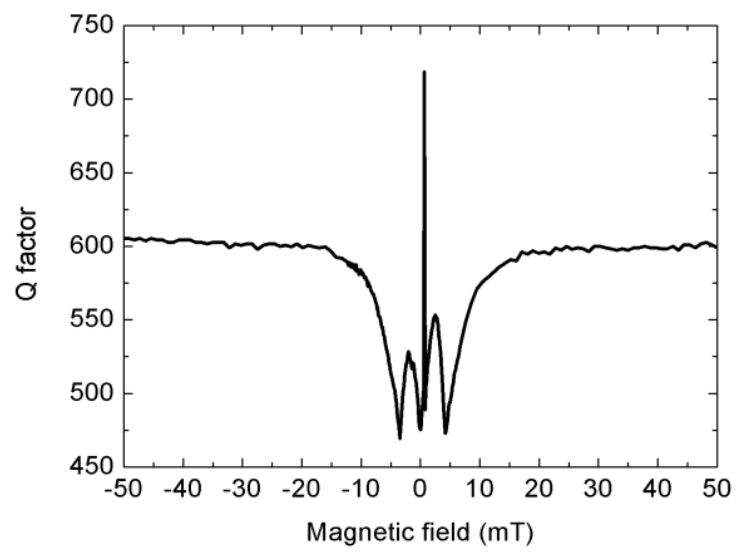

Fig. 16. The measured $\mathrm{Q}$ factor of the Love wave mode on $\mathrm{CoFeB} / \mathrm{SiO}_{2} / \mathrm{ZnO} / \mathrm{ST}+90^{\circ}$-cut quartz as a function of an applied external magnetic field along the hard axis.

\section{CONCLUSION}

In this study, we developed a numerical model to successfully determine the response of multilayered SAW devices to both temperature as well as magnetic field. The simulated responses were also successfully validated by experimental results.

A Love wave mode on the $\mathrm{CoFeB} / \mathrm{SiO}_{2} / \mathrm{ZnO} /$ quartz structure with a zero TCF is also discussed as an improvement over the $\mathrm{CoFeB} / \mathrm{ZnO} /$ quartz device with respect to an enhanced magnetic field sensitivity and $S_{11}$ response. The sensor response is improved by adding the $\mathrm{SiO}_{2}$ layer. The addition of $\mathrm{SiO}_{2}$ layer brings a new degree of liberty leading to achieve zero TCF devices with various combinations of $\mathrm{ZnO}$ and $\mathrm{SiO}_{2}$ thicknesses. More flexibility is then allowed to further design reliable and high performance magnetic field SAW sensors including in Giga Hertz frequency bands.

\section{ACKNOWLEDGMENT}

We would like to acknowledge the support from the French PIA project "Lorraine Université d'Excellence" (ANR-15IDEX-04-LUE) and ANR JCJC SAWGOOD (ANR-18-CE420004-01). Part of experiments were carried out on IJL Project TUBE-Davm equipment funded by FEDER (EU), Region Grand Est, Metropole Grand Nancy.

\section{REFERENCES}

[1] M. J. Dapino, R. C. Smith, F. T. Calkins, et al. A magnetoelastic model for Villari-effect magnetostrictive sensors. North Carolina State University. Center for Research in Scientific Computation, 2002.

[2] H. Zhou, A. Talbi, N. Tiercelin, et al. Multilayer magnetostrictive structure based surface acoustic wave devices. Applied Physics Letters, 2014, 104(11): 114101.

[3] M. J. Dapino. On magnetostrictive materials and their use in adaptive structures. Structural Engineering and Mechanics, 2004, 17(3-4): 303330.

[4] W. P. Robbins, A. Young. SAW phase modulator using magnetostrictive thin films. IEEE transactions on sonics and ultrasonics, 1985, 32(3): 423-427.

[5] M. Elhosni, O. Elmazria, S. Petit-Watelot, et al. Magnetic field SAW sensors based on magnetostrictive-piezoelectric layered structures: FEM modeling and experimental validation. Sensors and Actuators A: Physical, 2016, 240: 41-49.

[6] V. Polewczyk, K. Dumesnil, D. Lacour, et al. Unipolar and bipolar high-magnetic-field sensors based on surface acoustic wave resonators. Physical Review Applied, 2017, 8(2): 024001.

[7] H. Mishra, M. Hehn, D. Lacour, et al. Intrinsic versus shape anisotropy in micro-structured magnetostrictive thin films for magnetic surface acoustic wave sensors. Smart Materials and Structures, 2019, 28(12):12LT01.

[8] W. P. Robbins, A. Hietala. A simple phenomenological model of tunable SAW devices using magnetostrictive thin films. IEEE transactions on ultrasonics, ferroelectrics, and frequency control, 1988, 35(6): 718-722.

[9] W. Wang, Y. Jia, X. Liu, et al. Performance improvement of the SAW based current sensor incorporating a strip-patterned magnetostrictive FeCo film. 2017 IEEE International Ultrasonics Symposium (IUS). IEEE, 2017: 1-3.

[10] M. Kadota, S. Ito. Sensitivity of surface acoustic wave magnetic sensors composed of various $\mathrm{Ni}$ electrode structures. Japanese Journal of Applied Physics, 2012, 51(7S): 07GC21-1-5.

[11] M. Yamaguchi, K. Hashimoto, H. Kogo, et al. Variable SAW delay line using amorphous $\mathrm{TbFe}_{2}$ film. IEEE Transactions on Magnetics, 1980, 16(5): 916-918. 
[12] W. Wang, Y. Jia, X. Xue, et al. Grating-patterned FeCo coated surface acoustic wave device for sensing magnetic field. Aip Advances, 2018, 8(1): 015134

[13] P. Smole, W. Ruile, C. Korden, et al. Magnetically tunable SAWresonator. IEEE International Frequency Control Symposium and PDA Exhibition Jointly with the 17th European Frequency and Time Forum, 2003. Proceedings of the 2003. IEEE, 2003: 903-906.

[14] W. Li, P. Dhagat, A. Jander. Surface acoustic wave magnetic sensor using galfenol thin film. IEEE transactions on magnetics, 2012, 48(11): 4100-4102.

[15] A. Kittmann, P. Durdaut, S. Zabel, et al. Wide band low noise love wave magnetic field sensor system. Scientific reports, 2018, 8(1): 278.

[16] M. Hoummady, A. Campitelli, W. Wlodarski. Acoustic wave sensors: design, sensing mechanisms and applications. Smart materials and structures, 1997, 6(6): 647-657.

[17] H. Mishra, J. Streque, M. Hehn, et al. Temperature compensated magnetic field sensor based on love waves. Smart Materials and Structures, 2020, 29(4): 045036.

[18] Y. Yang, H. Mishra, Q. Z. Zhang, S. Hage-Ali, T. Han, O. Elmazria, A Weak Form Nonlinear Model for Thermal Sensitivity of Love Wave Mode on Layered Structures. IEEE Transactions on Ultrasonics, Ferroelectrics, and Frequency Control, 2020.

[19] H. B. Huang, J. M. Hu, T. N. Yang, et al. Strain-assisted currentinduced magnetization reversal in magnetic tunnel junctions: A micromagnetic study with phase-field microelasticity. Applied Physics Letters, 2014, 105(12): 122407.

[20] H. Zhou, A. Talbi, N. Tiercelin, et al. Theoretical and experimental study of multilayer piezo-magnetic structure based surface acoustic wave devices for high sensitivity magnetic sensor, 2013 IEEE International Ultrasonics Symposium (IUS). IEEE, 2013: 212-215.

[21] H. F. Tiersten, Perturbation theory for linear electroelastic equations for small fields superposed on a bias, J. Acoust. Soc. Am. 1978, 64 (3): 832-837.

[22] B. F. Miao, Y. T. Millev, L. Sun, et al. Thickness-driven spin reorientation transition in ultrathin films. Science China Physics, Mechanics and Astronomy, 2013, 56(1): 70-84.

[23] A. Gayen, G. K. Prasad, S. Mallik, et al. Effects of composition, thickness and temperature on the magnetic properties of amorphous CoFeB thin films. Journal of Alloys and Compounds, 2017, 694: 823832.

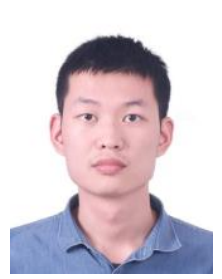

Yang Yang was born in Jiangsu, China. He received the BE degree from University of Electronic Science and Technology of China in 2015. He is currently a Ph.D. student at School of Electronic Information and Electrical Engineering in Shanghai Jiao Tong University. His current research interests include wireless surface acoustic wave sensors and signal processing.

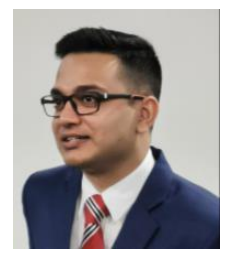

Harshad Mishra was born in Odisha, India, in 1989. He received his Ph.D. degree from Institut Jean Lamour, Université de Lorraine, France in 2019. Prior to that, he received his M.S. degree from IIT Madras, India in 2016. $\mathrm{He}$ is currently a post-doctoral researcher at Aalto University, Finland. His research interests include the development and optimization of magnetic field sensors using micro-structured magnetoelastic thin films, devices based on surface acoustic waves, nanofabrication technologies and exploring the interactions between elastic waves and magnons at the mechanical quantum limit.

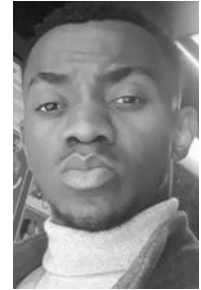

Prince Mengue was born in Oyem, Gabon, in 1992. He received his Master's degree in theoretical electronic physics at the University of Science and Technique of Masuku Franceville, Gabon, in 2017. He is currently $\mathrm{PhD}$. Student at Université de Lorraine within Micro and NanoSystems group of Jean Lamour Institute, Nancy, France. His research interests concern development low profile SAW sensors on metallic substrate for a direct integration on metallic equipment operating in harsh conditions.

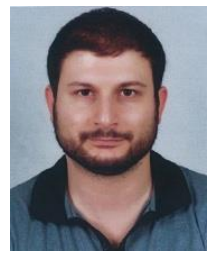

Sami Hage-Ali was born in Strasbourg, France, in 1982. He received an Engineering Degree from Ecole Centrale de Lille and a M.S in micro-nanotechnology from University of Lille 1 in 2005. He received another Master's Degree in international projects engineering from University of Lille 1 in 2006. He received a Ph.D. in micro-nanotechnology, acoustics and telecommunications from Ecole Centrale de Lille in 2011. In 2011, Dr Hage-Ali was awarded a Fulbright grant and became a post-doctoral fellow at the University of Illinois at Urbana-Champaign, USA. Since 2014, he is an Associate professor at Université de Lorraine and is with the Micro-nanosystems group of Institut Jean Lamour, Nancy, France. Dr Hage-Ali's areas of research are: surface acoustic wave sensors, flexible/stretchable electronics, micronanosystems, microwaves and antennas. $\mathrm{He}$ is currently serving as chairman of the IEEE France Section Sensors Council Chapter.

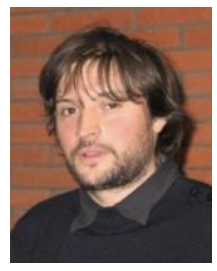

Sébastien Petit-Watelot is a professor at Université de Lorraine, Institut Jean Lamour, Nancy, France. His research interests include spintronics, nanomagnetism, nanoelectronics, and nanomagnetic materials.

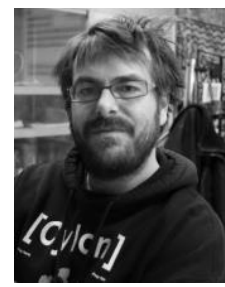

Daniel Lacour is a condensed mater physicist. After a PhD (1999-2002) dedicated to tunnel magneto-resistance and its applications (done in close collaboration between Université de Lorraine and the laboratory of A. Fert the 2007 Nobel prize winner) D. Lacour worked as postdoctoral fellow at the Hitachi GST laboratory of San Jose CA (20032005). During this period, he studied magnetic nano-devices. In 2006 he was appointed to the CNRS (National Center for Scientific Research), Nancy, France as research staff member. His field of expertise addresses Spintronic and Nanomagnetism. Taking profit of the fundamental knowledge he has acquired on the behavior of magnetic materials at the micro nanos/scale D. Lacour spent a part of his time research time on the development of sensors having a working principle based on magnetic material. 


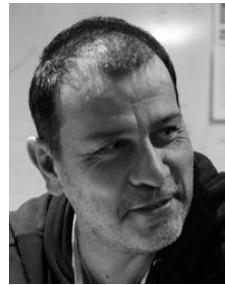

Michel Hehn received the Ph.D. degree from the University of Strasbourg in 1996, joined the French National Center of Scientific Research in 1998 and became professor at University de Lorraine in 2006. $\mathrm{He}$ is a specialist in material growth and in nanomagnetism/spintronics. In 2010, he won the Yves Rocard 2010 Price of the French Society of Physics for the invention and the technological development of "a new generation of magnetic sensors for ASB" for the SNR society. Pr. Hehn co-authored more than 240 papers in refereed international journals and in proceeding of international conferences.

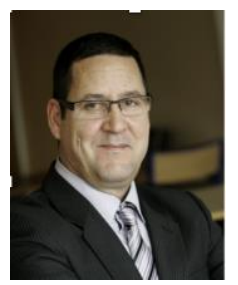

Hamid M'Jahed received his Master's degree in electronics and industrial automation in 2003. He joined the Institut Jean Lamour as permanent CNRS (National Center for Scientific Research) staff. He is now a CNRS engineer in RF and Electronics. His main research interests include study and realization of system query for SAW wireless sensors. In 2011, he received the Crystal award as the best Engineer in CNRS.

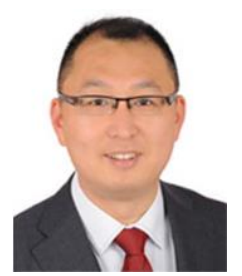

Tao Han was born in Shandong, China, in 1973. He received the Ph.D. degree in instrument science and technology from Shanghai Jiao Tong University, Shanghai, China, in 2002. He was a Visiting Scholar with Tohoku University, Sendai, Japan, in 2003. He is currently a professor at School of Electronic Information and Electrical Engineering in Shanghai Jiao Tong University. His current research interests include acoustic wave devices simulation, wireless surface acoustic wave sensors system, and ultrasound-based measurement. Prof. Han is a Technical Program Committee Member of the IEEE Ultrasonics Symposium.

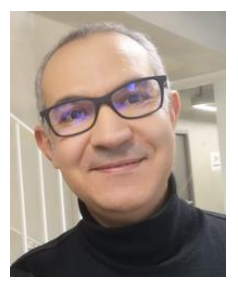

Omar Elmazria is a Full Professor (Exceptional Class) at Université de Lorraine (UL) within Institut Jean Lamour (IJL UMR 7198) for research and Polytech Nancy for teaching. He is also an emeritus member of the IUF (Institut Universitaire de France) and was guest Professor at several Universities around the world (SFU, Canada; IoA, Chinees Academy of Sciences; UCF, USA). His current research focuses on SAW devices for communication systems and sensing applications. He is the author and co-author of more than 180 international scientific articles, 4 international patents issued, and more than 120 communications in international conferences. In 2017, he receives URSI-France medal from the International Union of Radio Science. 